\title{
Possibilities of the use of composition of the extract of hemp to reduce the number of spider mites (Tetranychidae)
}

\author{
Wykorzystanie kompozycji z olejku konopnego \\ do ograniczania liczebności przędziorków (Tetranychidae)
}

\author{
Żaneta Fiedler ${ }^{1}$, Danuta Sosnowska ${ }^{1}$, Ryszard Kaniewski ${ }^{2}$, Maria Władyka-Przybylak ${ }^{2}$
}

\begin{abstract}
Summary
Biological control methods are considered as a priority and one of the most important elements of integrated plant protection, both in greenhouse grown and field crops. Tetranychus urticae and $T$. cinnabarinus are the most important pests occurring in greenhouse crops and successful control of these pests is very difficult. The present study determined the effectiveness of the composition of hemp oil in reducing the number of selected species of spider mites. The experiments in the laboratory revealed high efficacy in reducing of oil hemp in reducing $T$. urticae population $-82 \%$ mortality of larvae and $91 \%$ mortality of adult mites. Lower effectiveness was recorded in reducing the number of $T$. cinnabarinus $-75 \%$ mortality of larvae and $87 \%$ mortality of adult mites. The composition of the hemp oil was used at concentrations from 0.1 to $0.5 \%$, and the highest efficiency was observed at highest concentration. Hemp oil was ineffective in control of eggs of the two species included in the experiment. Nevertheless, the results are very promising and might be an important element in the development of integrated protection programs for vegetables and ornamental plants grown in greenhouses
\end{abstract}

Key words: Tetranychus urticae, Tetranychus cinnabarinus, extract of hemp oil

\section{Streszczenie}

Do najgroźniejszych szkodników roślin szklarniowych należą przędziorki, które atakują większość roślin ozdobnych oraz warzyw, powodując ogromne straty w plonach. Zwalczanie tej grupy szkodników jest bardzo trudne, gdyż w związku z występowaniem kilkunastu pokoleń w ciągu roku, obserwuje się zjawisko szybkiego nabywania odporności tych szkodników na środki chemiczne. W praktyce ochrony roślin coraz większe zastosowanie w zwalczaniu przędziorków znajdują różne czynniki biologiczne, w tym akarifagi. W związku ze zbliżającym się terminem wejścia w życie ustawy dotyczącej integrowanej ochrony roślin poszukuje się optymalnych rozwiązań w zwalczaniu szkodników i chorób, alternatywnych do środków chemicznych. W badaniach określono skuteczność działania kompozycji z olejku konopnego w ograniczaniu liczebności przędziorków (przędziorek chmielowiec - Tetranychus urticae, przędziorek szklarniowiec - T. cinnabarinus). Przeprowadzone doświadczenia w warunkach laboratoryjnych wykazały wysoką skuteczność olejku konopnego stosowanego w formie opryskiwania w ograniczaniu liczebności T. urticae - $82 \%$ śmiertelności larw oraz 91\% śmiertelności dorosłych przędziorków. Mniejszą skuteczność odnotowano w ograniczaniu liczebności T. cinnabarinus - 75\% śmiertelności larw i 87\% śmiertelności dorosłych przędziorków, w wyniku zanurzania liści. Kompozycję z olejku konopnego stosowano w koncentracjach od 0,1 do 0,5\% i największą skuteczność obserwowano przy stosowaniu najwyższej koncentracji, tj. 0,5\%. Olejek konopny okazał się nieskuteczny w zwalczaniu jaj obydwu zastosowanych w doświadczeniu gatunków przędziorków. Uzyskane wyniki są bardzo obiecujące i mogą być ważnym elementem w opracowywaniu programów integrowanej ochrony warzyw i roślin ozdobnych uprawianych pod osłonami.

Słowa kluczowe: Tetranychus urticae, Tetranychus cinnabarinus, olejek konopny

\footnotetext{
${ }^{1}$ Instytut Ochrony Roślin w Poznaniu - Państwowy Instytut Badawczy Władysława Węgorka 20, 60-318 Poznań

Z.Fiedler@iorpib.poznan.pl; Danuta.Sosnowska@iorpib.poznan.pl

${ }^{2}$ Instytut Włókien Naturalnych i Roślin Zielarskich

Wojska Polskiego 71b, 60-630 Poznań
} 


\section{Wstęp / Introduction}

W uprawie zarówno warzyw, jak i roślin ozdobnych pod osłonami występują głównie dwa gatunki przędziorków: przędziorek chmielowiec (Tetranychus urticae Koch) oraz przędziorek szklarniowiec (T. cinnabarinus Bois.). Na plantacjach zaatakowanych przez przędziorki następuje znaczne obniżenie plonu, w skrajnych przypadkach może być konieczna nawet likwidacja silnie opanowanej uprawy. Zwalczanie tej grupy szkodników jest bardzo trudne, gdyż w związku z występowaniem kilkunastu pokoleń w ciągu roku, obserwuje się zjawisko szybkiego nabywania odporności przez przędziorki na środki chemiczne. W praktyce ochrony roślin coraz większe zastosowanie znajdują różne czynniki biologiczne, w tym akarifagi, środki biotechniczne, czy inne oparte na naturalnych substancjach. W związku ze zbliżającym się terminem wejścia w życie ustawy dotyczącej integrowanej ochrony roślin poszukuje się optymalnych rozwiązań w zwalczaniu szkodników i chorób, alternatywnych do środków chemicznych.

W ostatnich latach zwiększył się areał uprawy konopi w Polsce i Europie dla celów przemysłowych. Warunki do rozwoju produkcji konopi w Polsce są dobre, często lepsze niż w innych krajach europejskich. Niskie ceny ziemi, niska cena pracy najemnej, duża dostępność oraz brak zanieczyszczenia gleb azotem, metalami ciężkimi i przyjazne warunki klimatyczne są dobrymi warunkami dla prawidłowego przebiegu uprawy konopi w naszym kraju. W związku z powyższym zwiększyło się zainteresowanie uprawą tej rośliny. Powstały nowe firmy, które rozpoczęły działalność w zakresie kontraktacji i tworzenia bazy przetwórczej. Efektem ich działalności jest wzrost areału uprawy konopi z 80 ha w 2003 roku do około 1000 ha $\mathrm{w}$ roku 2012. Długi czas wiechy konopne były przeznaczone głównie na cele opałowe lub traktowane jako bezużyteczny odpad. W Instytucie Włókien Naturalnych i Roślin Zielarskich w Poznaniu opracowano nową technologię, w której możliwe jest oddzielenie wiech podczas zbioru. $\mathrm{Z}$ tych wiech, w drodze destylacji $\mathrm{z}$ para wodną, można otrzymać olejek eteryczny, który jest wykorzystywany do produkcji artykułów kosmetycznych, spożywczych, np. alkoholowych (Burczyk i Kaniewski 2007; Kaniewski 2008, 2011, 2012).

Olejek eteryczny z konopi może również znaleźć zastosowanie $\mathrm{w}$ ochronie roślin ze względu na zawarte w nim liczne związki chemiczne, z których część wykazuje dużą aktywność w stosunku do szkodników.

Celem badań było określenie skuteczności kompozycji $\mathrm{z}$ olejku konopnego w ograniczaniu liczebności różnych stadiów rozwojowych przędziorków Tetranychus urticae i T. cinnabarinus.

\section{Materiały i metody / Materials and methods}

Doświadczenia przeprowadzono w warunkach laboratoryjnych na liściach ogórka szklarniowego, odmiana Colonel. Przędziorek chmielowiec i przędziorek szklarniowiec pochodził $\mathrm{z}$ hodowli prowadzonej w szklarniach Instytutu Ochrony Roślin - Państwowego Instytutu Ba- dawczego w Poznaniu. Wykorzystywany olejek eteryczny był wyprodukowany z polskich odmian konopi, takich jak: Beniko, Białobrzeskie i Silesia, o niskiej zawartości kanabinoidów, w tym THC - TetraHydroCanabinol (poniżej 0,2\% w suchej masie ziela). Odmiany te spełniają wymagania określone w ustawie, $\mathrm{z}$ dnia 29 lipca 2005 roku, o przeciwdziałaniu narkomanii (Dz.U. z dnia 19 września 2005 r.) i są dopuszczone do uprawy w kraju.

Do płytek Petriego (średnica $9 \mathrm{~cm}$ ) wkładano liście ogórka szklarniowego naturalnie zasiedlone przez przędziorki (różne stadia rozwojowe). Pierwsze doświadczenia polegały na opryskiwaniu liści $\mathrm{z}$ danym gatunkiem przędziorka olejem konopnym w stężeniach 0,$1 ; 0,2 ; 0,3$; 0,$4 ; 0,5 \%$. Kontrolą były liście opryskiwane tylko wodą destylowaną. Do każdego rozcieńczenia dla uzyskania jednorodnej emulsji wodnej dodawany był adiuwant Triton (0,02 $\mathrm{ml} / 1$ wody). Druga część doświadczenia polegała na zanurzaniu w wyżej wymienianych stężeniach olejku konopnego liści ogórka naturalnie zasiedlonych różnymi stadiami szkodników $\mathrm{w}$ roztworze wodnym $\mathrm{z}$ olejkiem konopnym. Zanurzenie trwało 2 sekundy, a następnie przenoszono liść do płytki Petriego. Wszystkie kombinacje wykonane zostały w pięciu powtórzeniach. Obserwacje prowadzono co 24 godziny do 14 dni, licząc żywe i martwe osobniki szkodnika, z rozdzieleniem na stadia rozwojowe. Doświadczenia były wykonane w warunkach kontrolowanych, w temperaturze $25^{\circ} \mathrm{C}$.

Wyniki badań poddano analizie wariancji (ANOVA) przy poziomie istotności $\alpha<0,05$, a wartości średnie porównywano testem Tukeya w celu wykazania istotnych różnic pomiędzy wariantami.

\section{Wyniki i dyskusja / Results and discussion}

W wyniku przeprowadzonych doświadczeń w warunkach laboratoryjnych stwierdzono różną skuteczność działania kompozycji z olejku konopnego w stosunku do dwóch zastosowanych gatunków przędziorków, jak i do różnych stadiów rozwojowych szkodników (tab. 1, 2).

Stwierdzono wysoką skuteczność działania olejku z konopi w zwalczaniu zarówno przędziorka chmielowca, jak i przędziorka szklarniowca. Wyższą efektywność olejku konopnego obserwowano jednak w ograniczaniu liczebności T. urticae - 82\% śmiertelności larw oraz 91\% śmiertelności dorosłych przędziorków po 14 dniach od zabiegu opryskiwania (tab. 1). Mniejszą skuteczność odnotowano w ograniczaniu liczebności T. cinnabarinus $75 \%$ śmiertelności larw i 87\% śmiertelności dorosłych przędziorków po 14 dniach od zabiegu zanurzania w olejku konopnym (tab. 2). Kompozycję z olejku konopnego stosowano w koncentracjach od 0,1 do 0,5\% i największą skuteczność obserwowano przy stosowaniu najwyższej koncentracji, tj. 0,5\%. W mniejszych koncentracjach uzyskano śmiertelność na poziomie tylko kilkunastu procent. Olejek konopny okazał się nieskuteczny w zwalczaniu jaj obydwu gatunków przędziorków, co można było obserwować przez zwiększająca się liczbę larw w kolejnych obserwacjach. Nie odnotowano także istotnych różnic w zastosowaniu olejku konopnego przez opryskiwanie lub zanurzanie liści. 
Tabela 1. Liczebność i procent śmiertelności przędziorka chmielowca po zastosowaniu olejku konopnego poprzez opryskiwanie w warunkach laboratoryjnych

Table 1. Number and percentage of mortality of T. urticae after application of hemp oil in laboratory conditions

\begin{tabular}{|c|c|c|c|c|}
\hline \multicolumn{5}{|c|}{$\begin{array}{l}\text { Liczebność przędziorka chmielowca (T. urticae) } \\
\text { Number of two-spotted spider mite (T. urticae) }\end{array}$} \\
\hline \multirow{2}{*}{$\begin{array}{l}\text { Warianty } \\
\text { Treatments }\end{array}$} & \multicolumn{2}{|c|}{$\begin{array}{l}\text { nimfy } \\
\text { nymhs }\end{array}$} & \multicolumn{2}{|c|}{$\begin{array}{c}\text { postacie dorosłe } \\
\text { adults }\end{array}$} \\
\hline & $\begin{array}{l}\text { przed } \\
\text { before }\end{array}$ & $\begin{array}{l}\text { po } 14 \text { dniach } \\
\text { after } 14 \text { days }\end{array}$ & $\begin{array}{l}\text { przed } \\
\text { before }\end{array}$ & $\begin{array}{l}\text { po } 14 \text { dniach } \\
\text { after } 14 \text { days }\end{array}$ \\
\hline $0,1 \%$ & 49 & $43(12 \%) b$ & 34 & $31(9 \%) b$ \\
\hline $0,2 \%$ & 33 & $30(9 \%) b$ & 20 & $18(10 \%) b$ \\
\hline $0,3 \%$ & 28 & $20(28 \%) b$ & 15 & $10(33 \%) \mathrm{c}$ \\
\hline $0,4 \%$ & 36 & $12(67 \%) \mathrm{cd}$ & 26 & $6(77 \%) d$ \\
\hline $0,5 \%$ & 35 & $7(82 \%) d$ & 34 & $3(91 \%) d$ \\
\hline Kontrola - Control & 34 & $95(0 \%) \mathrm{a}$ & 28 & $49(0 \%) \mathrm{a}$ \\
\hline
\end{tabular}

Wartości w kolumnach oznaczone różnymi literami różnią się istotnie ( $\mathrm{p}<0,05$, test Tukeya)

Values within each column followed by the different letter are significantly different $(\mathrm{p}<0.05$, Tukey's test)

Tabela 2. Liczebność i procent śmiertelności przędziorka szklarniowca po zastosowaniu olejku konopnego poprzez zanurzanie Table 2. Number and percentage of mortality of red spider mite after using hemp oil dipping

\begin{tabular}{|c|c|c|c|c|}
\hline \multicolumn{5}{|c|}{$\begin{array}{c}\text { Liczebność przędziorka szklarniowca (T. cinnabarinus) } \\
\text { Number of red spider mite (T. cinnabarinus) }\end{array}$} \\
\hline \multirow{2}{*}{$\begin{array}{l}\text { Warianty } \\
\text { Treatments }\end{array}$} & \multicolumn{2}{|c|}{$\begin{array}{l}\text { nimfy } \\
\text { nymhs }\end{array}$} & \multicolumn{2}{|c|}{$\begin{array}{l}\text { postacie dorosłe } \\
\text { adults }\end{array}$} \\
\hline & $\begin{array}{l}\text { przed } \\
\text { before }\end{array}$ & $\begin{array}{l}\text { po } 14 \text { dniach } \\
\text { after } 14 \text { days }\end{array}$ & $\begin{array}{l}\text { przed } \\
\text { before }\end{array}$ & $\begin{array}{l}\text { po } 14 \text { dniach } \\
\text { after } 14 \text { days }\end{array}$ \\
\hline $0,1 \%$ & 35 & $34(3 \%) \mathrm{a}$ & 22 & $19(13 \%) b$ \\
\hline $0,2 \%$ & 24 & $21(12 \%) b$ & 26 & $25(4 \%) \mathrm{a}$ \\
\hline $0,3 \%$ & 28 & $13(54 \%) \mathrm{c}$ & 20 & $18(10 \%) b$ \\
\hline $0,4 \%$ & 20 & $6(70 \%) d$ & 34 & $9(73 \%) \mathrm{c}$ \\
\hline $0,5 \%$ & 32 & $8(75 \%) d$ & 22 & $3(87 \%) c$ \\
\hline Kontrola-Control & 34 & $102(0 \%) \mathrm{a}$ & 38 & $52(0 \%) \mathrm{a}$ \\
\hline
\end{tabular}

Wartości w kolumnach oznaczone różnymi literami różnią się istotnie ( $\mathrm{p}<0,05$, test Tukeya)

Values within each column followed by the different letters are significantly different $(\mathrm{p}<0.05$, Tukey's test)

W literaturze jest niewiele informacji na temat wykorzystania konopi siewnej w zwalczaniu szkodników. Grewal (1989) stwierdziła toksyczne działanie suszonych liści konopi na nicienia Aphelonchoides composticola, atakującego strzępki grzybów uprawnych. Liście te dodawano do kompostu używanego do produkcji pieczarki dwuzarodnikowej. Udowodniono również, że konopie siewne działają repelentnie. Rothschild i Fairbairn (1980) zaobserwowali odstraszające działanie wyciąów z konopi na bielinka kapustnika (Pieris brassicae), a Metzger i Grant ( 1932) na popilię japońską (Popillia Japonia). Silne właściwości toksyczne w stosunku do szkodników wykazują wodne i alkoholowe ekstrakty z konopi siewnej. Stwierdzono silne ich oddziaływanie na stonkę ziemniaczaną (Leptinotarsa decemlineata) (Stratii 1976) oraz nicienie takich gatunków, jak: Heterodera cajani, Hoplolaimus indicus i Tylechorynchus brassicae (Mojumder i wsp. 1989). Zdaniem McPartlanda (1997) efektywność działania wyciągów $\mathrm{z}$ konopi siewnych zależy między innymi od tego, jaka część rośliny została wykorzystana, od fazy rozwojowej roślin w czasie zbioru, ilości użytego materiału roślinnego i rozpuszczalnika oraz czasu i temperatury ekstrakcji.

W Polsce były wykonywane także badania na określenie skuteczności działania olejku konopnego w zwalczaniu mszycy jabłoniowo-babkowej (Dysaphis plantaginea Pass.) na jabłoni. Wyniki wykazywały podobną efektywność działania olejku konopnego, jak insektycydu Mospilan 20 SP. Po 24 godzinach od wykonania zabiegu odnotowano 93\% śmiertelności szkodnika (Górski i wsp. 2009). Wyciagiem wodnym z konopi siewnej zaprawiano również nasiona marchwi badając ich zdrowotność, kiełkowanie oraz ograniczanie chorób powodowanych przez patogeny grzybowe $\mathrm{z}$ rodzaju Alternaria sp. Zastosowanie wyciagu poprawiło zdolność kiełkowania nasion oraz zmniejszyło liczbę siewek $\mathrm{z}$ objawami chorobowymi (Dorna i wsp. 2010). Wszystkie te badania potwierdzają możliwość wykorzystania olejku konopnego zarówno w ograniczaniu chorób, jak i liczebności szkodników roślin. 


\section{Wnioski / Conclusions}

1. Przeprowadzone w warunkach laboratoryjnych doświadczenia wykazały wysoką skuteczność olejku konopnego w ograniczaniu liczebności larw i dorosłych osobników T. urticae i T. cinnabarinus.

2. Kompozycję z olejku konopnego stosowano w koncentracjach od 0,1 do $0,5 \%$ i największą skuteczność obserwowano przy stosowaniu najwyższej koncentracji, tj. 0,5\%.

3. Olejek konopny okazał się nieskuteczny w zwalczaniu jaj obydwu gatunków przędziorków zastosowanych w doświadczeniu.
4. Nie odnotowano istotnych różnic w zastosowaniu olejku konopnego poprzez opryskiwanie lub zanurzanie liści.

Patent WIPO ST 10/C PL394918 „Kompozycja przeciwko szkodnikom, zwłaszcza przędziorkom, sposób wytwarzania kompozycji oraz zastosowanie do zwalczania szkodników".

\section{Literatura / References}

Burczyk H., Kaniewski R. 2007. Konopie włókniste źródłem olejków eterycznych. Pam. Puł. 151 (1): 37-47.

Dorna H., Kaniewski R., Jarosz M., Banach J., Szocińska D. 2010. Zdrowotność i kiełkowanie nasion marchwi traktowanych wyciagiem wodnym $\mathrm{z}$ konopi siewnych (Cannabis sativa L.). [Health and germination of carrot seeds treated with aqueous extract from hemp (Cannabis sativa L.)]. Prog. Plant Prot./Post. Ochr. Roślin 50 (1): 373-377.

Grewal P.S. 1989. Effect of Lear-matter incorporation on Aphelenchoides composticola (Nematoda), mycofloral composition, mushroom compost quality and yield of Agaricus bisporus. Ann. Apel. Biol. 115: 299-312.

Górski R., Szklarz M., Kaniewski R. 2009. Skuteczność olejku eterycznego z konopi siewnej w zwalczaniu mszycy jabłoniowobabkowej (Dysaphis plantaginea Pass.) występującej na jabłoni. [Efficacy of hemp essential oil in the control of rosy apple aphid (Dysaphis plantaginea Pass.) occurring on apple tree]. Prog. Plant Prot./Post. Ochr. Roślin 49 (4): 2013-2016.

Kaniewski R. 2008. Możliwość wykorzystania konopi włóknistych - Cannabis sativa L. w biologicznych preparatach ochrony roślin. Biul. Informacyjny Polskiej Izby Lnu i Konopi 9: 28-34.

Kaniewski R. 2011. Renewable Resources and Biotechnology for Material Application, Materials Science and Technologies. Nova Science Publishers, Inc. New York, 1450 pp.

Kaniewski R. 2012. Instalacja do produkcji eterycznych olejków w zakładzie doświadczalnym. Biul. Informacyjny Polskiej Izby Lnu i Konopi 10: 66-70.

McPartland J.M. 1997. Cannabis as repelent and pesticide. J. Int. Hemp. Assoc. 4 (2): 87-92.

Metzger F.W., Grant D.H. 1932. Repellency to the Japanese beetle of extract made from plants immune to attack. USDA Technical Bull. 299, p. 21.

Mojumder V., Mishra S.D., Haque M.M., Goswami B.K. 1989. Nematicidal efficacy of some wild plants against pigeon pea cyst nematode Heterodera cajani. Int. Nematol. Network Newsletter 6 (2): 21-24.

Rothschild M., Fairbairn J.W. 1980. Ovipositing butterfly (Pieris brassicae) distinguishes between aqueous extracts of two strains Cannabis sativa and THC and CBD. Nature 286: 56-59.

Stratii Y.I. 1976. Hem pand the Colorado beetle. Zashchita Rastenii 5, p. 61.

Ustawa z dnia 29 lipca 2005 r. o przeciwdziałaniu narkomanii, Dz.U. 2005.179.1485, z dnia 19 września 2005 r. 